\title{
PROCESOS MIGRATORIOS EN LA CENTROAMÉRICA DEL SIGLO XXI. NAYAR LÓPEZ CASTELLANOS (COORD.). CIUDAD DE MÉXICO: EDICIONES LA BIBLIOTECA, 2018
}

En épocas recientes, las migraciones han captado la atención como tema de análisis y discusión, en vista de los desafíos que presentan para nuestras sociedades, sean estos de origen, destino, tránsito o retorno. En este sentido, el texto coordinado por Nayar López Castellanos, titulado Procesos migratorios en la Centroamérica del siglo $X X I$, posiciona la temática en el centro del debate público global, pero con una mirada desde la región centroamericana. En sus nueve artículos y una presentación introductoria, el libro señala los diferentes aspectos que construyen la complejidad de las migraciones, los cuales van desde el recuento histórico de los desplazamientos hasta las recientes tendencias en la movilidad.

López Castellanos indica que el texto tiene dos objetivos principales. Por un lado, contribuir a la recuperación de Centroamérica como parte de la agenda de investigación, tras el olvido en el que cayó con el final de los conflictos armados en la década de 1990. Por otro, analizar la complejidad de los desplazamientos y sus impactos en la región, que van desde Panamá hasta Estados Unidos, con una perspectiva multidisciplinaria.

Los ejes analíticos principales que cohesionan los nueve artículos son: los efectos del neoliberalismo en la región, la violencia en sus diversas formas y las políticas de securitización de las migraciones. Con ellos, los autores logran hilar los enfoques teóricos, las causas de las migraciones y los contextos particulares y compartidos de la realidad centroamericana, resaltando los conflictos armados y las condiciones socioeconómicas de posguerra que constituyen la base para nuestras sociedades desiguales, violentas, excluyentes y fragmentadas.

López Castellanos presenta el primer artículo, "El Neoliberalismo en Centroamérica, balance de una época”, el cual sienta las bases para los próximos autores, con una introducción al contexto sociopolítico e histórico de la región. El autor realiza un recorrido por los países centroamericanos, de manera que resalta peculiaridades de cada uno; pero destaca, además, lo que tienen en común. Parte de la premisa 
de que tres décadas de globalización capitalista neoliberal, derivada del Consenso de Washington, han causado una grave crisis social que se traduce en dependencia estructural, pobreza y violencia. En este escenario, las guerras contrainsurgentes agravaron los problemas socioeconómicos, al reforzar los sistemas de explotación y dominación ya existentes.

Mientras tanto, los Estados han sufrido una reconversión de su papel, disminuyendo sus responsabilidades sociales y dejándolas en manos del mercado, con lo cual aumentó la pobreza y la desigualdad. Asimismo, se consolidó la función histórica de la región centroamericana como una periferia exportadora de materias primas y mano de obra dentro de la división internacional del trabajo; es decir, migración y maquila como "industrias" principales. A ello se une la dependencia estructural de ingresos externos, sean estos préstamos, remesas, donaciones o inversión extranjera directa, la "recolonización" del territorio por parte de empresas extranjeras y el narcotráfico y el crimen organizado como justificación para el intervencionismo de Estados Unidos.

El texto finaliza con la propuesta para un cambio de paradigma, donde se priorice a las personas como actores protagónicos de una democracia basada en derechos, se movilicen los sectores explotados y se establezcan alianzas multisectoriales. Además, con el aumento de la presencia de China en la región, plantea la posibilidad de establecer caminos propios y una mayor integración para una independencia económica y desarrollo soberano.

Luis Alfredo Arriola Vega es el autor del segundo artículo, "Aportes para evaluar el desempeño del Programa Frontera Sur", el cual se centra en México como territorio de tránsito. El autor indica que la migración es producto de un sistema capitalista mundial donde las políticas neoliberales han empeorado la situación de Centroamérica, incrementando los flujos migratorios y la violencia de posguerra, y por tanto, el desplazamiento forzado de personas necesitadas de protección internacional.

Parte de un contexto en el cual se combinan los elementos siguientes: por un lado, las políticas migratorias estadounidenses son cada vez más restrictivas y drásticas para el control de las fronteras, con lo cual aumentan las deportaciones, por otro, México es un "país-tapón" (desde una agenda de externalización de fronteras por parte de Estados Unidos) para frenar el flujo de personas. Dicho flujo es cada vez más diversificado entre migrantes tradicionales (jornaleros y trabajadoras del hogar) y migrantes internacionales. El sur de dicho país, además, tiene importancia geoestratégica para el tránsito de migrantes y el crimen organizado. En este escenario, el autor evalúa el Programa Frontera Sur y sus efectos en la región, a partir de la metodología de McConnell, que valora el continuum entre éxito y fracaso.

Arriola Vega indica que la política mexicana sobre la frontera sur ha sido incoherente y sin visión integral, desarticulada, sin sostenibilidad a largo plazo, en la cual se ha priorizado la seguridad de fronteras y no se han tomado en cuenta los aportes 
de la sociedad civil organizada en su formulación e implementación. El autor plantea tres criterios para evaluar el desempeño del Programa Frontera Sur: la brecha discursiva entre la norma y la praxis, la brecha operativa entre lo que dicta la norma y lo que se implementa y la brecha de efectividad entre lo esperado y los resultados reales. De acuerdo con la evaluación realizada por el autor, el Programa es producto de una serie de políticas fragmentadas, con iniciativas a corto plazo, destinado a la seguridad y control de las fronteras; ha tenido como resultado el fortalecimiento de las redes de traficantes de personas, el aumento de sus cuotas y la búsqueda de nuevas rutas para evadir controles oficiales. Todo ello ha aumentado también el peligro para las personas migrantes y su vulnerabilidad en la garantía de Derechos Humanos. En resumen, los resultados de su implementación son parciales, con críticas de la sociedad civil organizada en cuanto a diseño, transparencia y rendición de cuentas, pero con pocos beneficios para México.

El tercer artículo lo aportan Enrique Coraza de los Santos y Santiago Martínez Junco: "Atención a la población en situación de movilidad en el espacio transfronterizo México-Guatemala". En este se examinan las diversas formas de asociación de las poblaciones en situación de movilidad, las cuales construyen capital social y cultural en niveles locales, regionales y nacionales. Los autores distinguen entre organizaciones de migrantes y organizaciones para migrantes. Las primeras constituyen espacios de acción colectiva para la incidencia en diferentes temáticas, en tanto que las segundas generalmente están dirigidas hacia la atención en derechos humanos, asistencia humanitaria y otros servicios. Al respecto, se centran en las organizaciones para migrantes que existen en la ciudad de Tapachula, territorio donde interactúan cotidianamente dichas organizaciones, conformando un espacio transfronterizo de y para migrantes que habitan la ciudad.

Coraza y Martínez discuten sobre la importancia del asociacionismo migrante como una respuesta ante lo desconocido y hostil, como una necesidad de recrear espacios de pertenencia y generar lazos de solidaridad, así como de crear espacios de representación y visibilización. No obstante, Tapachula apenas cuenta con tres organizaciones de migrantes, dadas las barreras que existen para la creación de estas, las cuales se traducen en: dificultades legales, la ciudad como espacio de tránsito de una población desestructurada/fragmentada y la existencia de entidades que proporcionan atención o asistencia humanitaria en contextos de vulnerabilidad. Estas entidades compiten entre ellas por recursos, duplican servicios y, en general, no están integradas o articuladas entre sí. Dichos espacios (generalmente privados, pero también gubernamentales, de organismos internacionales o consulares) son sitios de espera que satisfacen necesidades primarias de protección, denuncia, entre otros. En este escenario, Tapachula se construye como una localidad transnacional donde están presentes las conexiones y continuidades en una frontera porosa, donde las personas migrantes son el vínculo que conecta lugares de origen, tránsito y destino. 
Matthew James Lorenzen Martiny, Obed Frausto Gatica y Zulia Yanzadig Orozco Reynoso son los autores del artículo "Neoliberalismo, violencia y migración de Centroamérica a los Estados Unidos. El caso de los menores migrantes no acompañados vistos desde el enfoque de las migraciones mixtas". Su punto de partida es el aumento de niñez migrante no acompañada entre 2011 y 2014, donde el $80 \%$ procede de los países del norte de Centroamérica, lo cual está vinculado al deterioro de la vida en sociedad, cuya marginalidad y opresión se conciben como "necropolítica". Dicho concepto se refiere a la generación de una ciudadanía "desechable", explotada, reemplazable y excluida del sistema económico neoliberal y autoritario desde las oligarquías.

Los autores hacen un recuento histórico de la implementación de las medidas neoliberales en los Estados de la región, las cuales causaron más desprotección de los derechos ciudadanos y, por consiguiente, más desplazamientos por violencia y falta de oportunidades. Plantean tres niveles de análisis de las migraciones: nivel micro, donde los migrantes pueden desplazarse por motivaciones mixtas; nivel meso, o flujos migratorios mixtos; y nivel macro, donde se intersectan múltiples causas estructurales. En este sentido, proponen el concepto de migraciones mixtas, pues la distinción entre voluntario y forzado se diluye en el contexto actual de globalización neoliberal en la región centroamericana, donde las causas de desplazamiento son múltiples y simultáneas.

El texto de Jenyel del Carmen Contreras Guzmán se titula "Centroamérica: región de desplazamientos forzados" y parte de indicar que existe una correlación entre la profundización de las políticas neoliberales y el aumento de flujos migratorios en la región latinoamericana (alrededor del $6 \%$ en las últimas dos décadas). Dichos flujos son diversos, con dinámicas particulares, pero se interrelacionan en una especie de sistema de migraciones que combina la migración interna, intrarregional y la internacional.

El autor argumenta que la migración es una dimensión "estructural y estructurante", la cual surge de procesos de exclusión y suple lo que ni el Estado ni el mercado proveen. En este sentido, las personas se ven forzadas a desplazarse con el desvanecimiento de las economías tradicionales y se convierten en "perdedores del ajuste". A ello se suman unas políticas migratorias, cada vez más restrictivas, que cierran fronteras, aumentan las deportaciones y posicionan la migración como un problema de seguridad y riesgo a la soberanía de los Estados. Estas restricciones incrementan la vulnerabilidad y precariedad de las personas migrantes, pues incrementan los costos humanos y económicos del tránsito, lo cual favorece al crimen organizado en un contexto de Estados debilitados que no cumplen con el derecho al desarrollo y, por tanto, con el derecho a no migrar.

Norma Angélica Cuéllar Díaz y Hugo César Moreno Hernández presentan el artículo titulado "Violencia, crisis humanitaria y migración forzada de Centroamérica", el cual expone a la región del "Triángulo Norte" como violenta y en crisis humanitaria, 
con gobiernos débiles, e inmersa en un contexto histórico de racismo y violencia institucionalizada a través de siglos de colonialismo y sistemas autoritarios. A ello se añaden décadas de imperialismo, neocolonialismo y un modelo liberal que favoreció la acumulación capitalista, la desposesión y la exclusión. En ese contexto, las pandillas en El Salvador constituyen el objeto de análisis del artículo.

Los autores indican que estas se posicionan como un enemigo transnacional a quien pueden culpar por la violencia delincuencial, lo cual oculta la violencia estructural. Así, son producto de la deportación masiva, las tensiones sociales, la desintegración familiar y la debilidad institucional. Dichos grupos pueden pasar por tres etapas: los crímenes oportunistas, el narcotráfico, la producción y comercialización de drogas y la consolidación de un cuerpo organizado con poder político con capacidad de influir en la vida pública. Son responsables de la huida forzada de miles de personas y familias enteras de El Salvador, a las cuales el Estado no reconoce como desplazados forzados internos.

Este escenario continuo de violencia estructural favorece la vulnerabilidad, las personas son una mercancía sometida a la explotación extrema (trata, tráfico, entre otros), lo cual beneficia tanto a las autoridades migratorias como a la delincuencia y al crimen organizado. Por ejemplo, la entrada en vigencia del Plan Frontera Sur en México aumentó la seguridad de la frontera, pero también los precios de las redes de coyotaje y las estrategias de las personas migrantes para el cruce irregular. Todo ello ocurre en relación con un discurso de doble moral desde el Norte, donde aumentan las deportaciones, pero se requiere de mano de obra mexicana y centroamericana dentro de un sistema capitalista global y transnacional que privilegia la acumulación de capital y mantiene las disparidades entre Norte y Sur.

El artículo de Luisa Alquisiras Terrones, “Migrantes centroamericanos mutilados en México: representaciones y políticas del cuerpo doliente", centra su análisis en la doble segregación que resulta de las mutilaciones que sufren las personas migrantes. Por un lado, se traduce en un abandono de la posibilidad de integración económica y social como fuerza de trabajo en Estados Unidos y, por otro, en la dependencia de acciones de buena voluntad y humanitarias por parte de organizaciones y personas.

Para la autora, esto se enmarca en el neoliberalismo que ha producido estructuras políticas y procesos de precariedad de las personas migrantes en el espacio transnacional desde el origen al destino. Así, el daño físico se vuelve una narrativa que atraviesa diferentes actores, tales como el Estado mexicano, las ONG, los medios de comunicación y los propios migrantes.

La autora plantea que los migrantes pueden ser considerados como excluidos inmanentes, pues están integrados en la economía capitalista en condiciones precarias y no están incluidos en la comunidad política. Asimismo, la flexibilización del mercado laboral y la precarización del trabajo se benefician de las políticas restrictivas de control migratorio, lo cual vuelve ilegal la contratación de migrantes irregulares y, 
por lo tanto, están sujetos a explotación como población "desechable", según Alquisiras. Este paradigma de securitización genera ideas sobre la población migrante como intrusos, peligrosos o competencia; surge, entonces, la biopolítica o el ejercicio de poder y regulación de la población entre deseables e indeseables, a través de detenciones, deportaciones y mayor control fronterizo.

En este contexto, examina de manera descriptiva las mutilaciones como una temática poco tratada en la literatura académica y plantea que, además de acentuar las barreras sociales que motivaron la emigración, suman nuevas dificultades ambientales y socioculturales relacionadas con la discapacidad. La persona mutilada está más excluida que antes y puede interrumpir definitivamente el desplazamiento. Se le reconoce como víctima sujeta de compasión, protección o ayuda, y como cuerpo doliente que reclama comprensión humanitaria. Ello pone en práctica procesos de biolegitimidad, donde se reconocen las desigualdades a las personas cuando existe dolor físico y, por tanto, el cuerpo doliente es una forma de acceso a la ciudadanía, derechos y compasión.

Blanca Laura Cordero Díaz y María Georgina Garibo García escriben el artículo "Violencias encarnadas: migración de mujeres centroamericanas", el cual examina las múltiples violencias en las migraciones de mujeres, desde lo micro hasta lo macro, las cuales tienen efectos sobre sus cuerpos, y la subjetividad de la experiencia en tránsito. Para las autoras, el proceso de migrar suma diferentes tipos de violencia, o violencias encarnadas, que despojan de manera diferenciada a las mujeres en diferentes etapas migratorias, especialmente si es un desplazamiento irregular.

Las autoras definen violencia como un acto de poder que implica fuerza (no necesariamente física) y utilizan el concepto triángulo de violencia, el cual relaciona la violencia estructural, cultural y directa. La estructural es la suma de choques en las estructuras sociales que producen resultados injustos y desiguales en las condiciones de la población. Implica cadenas de empobrecimiento, dependencia y despojo, donde no existe un victimario exclusivo, sino que este es invisible e indirecto. La violencia cultural es simbólica y se refiere a cualquier elemento que legitima la violencia estructural o directa, donde la víctima no la reconoce porque está normalizada. Por tanto, el victimario también es invisible. Por último, la violencia directa puede ser física o verbal, e implica un acto o conducta que realiza un actor visible sobre una víctima, cuyas consecuencias son notorias.

Los tres tipos de violencia se representan en los cuerpos, entornos, vidas y percepciones de las personas que las sufren, pues se manifiestan en no poder cubrir necesidades básicas de las poblaciones, el femicidio, la desnutrición y la migración, entre otros. Asimismo, cada una legitima a las demás y se expresan en las experiencias de mujeres centroamericanas en cuanto a relaciones de género violentas y de subordinación.

El artículo utiliza el concepto de despojo como herramienta analítica para explicar la violencia estructural y cómo esta produce multiplicidad de violencias 
encarnadas en las migraciones, en relación con el modelo de acumulación de capital. De esta manera, las potencias compiten por mercados y mano de obra barata y adquieren de manera legalizada recursos naturales (tierra) con ayuda del Estado, lo cual se traduce en despojo al amparo de las leyes y la política, con el consecuente desplazamiento de poblaciones. Dicho desplazamiento es parte de la conexión estructural entre la transnacionalización laboral y la globalización de la región centroamericana como parte de la periferia que provee fuerza de trabajo al sistema.

Salvador Marti i Puig y Nahún Alberto García Díaz presentan el último artículo, "La otra ruta migratoria de Honduras: el caso de Girona". En este se examina como estudio de caso la migración hondureña a España, país que se convierte en una alternativa, en vista de las políticas migratorias restrictivas a Estados Unidos.

En el texto se describe concretamente la ciudad de Girona, en Catalunya, donde la población hondureña ha llegado hace alrededor de una década. Dicha población no tiene conexiones familiares en Estados Unidos y empezó a emigrar tras el paso del huracán Mitch en 1999. Se trata de una migración de mujeres, en su mayoría, dirigida al cuidado doméstico.

Utiliza metodología mixta de encuestas y entrevistas con líderes y grupos focales, en combinación con información de censos, datos oficiales de ayuntamientos, de dos asociaciones de hondureños en Catalunya, y de asociaciones que trabajan con población migrante. Los datos muestran una población hondureña principalmente femenina, la cual trabaja extensas horas con salarios bajos, dedicada a servicios domésticos y cuidado de mayores, principalmente. Muestra de manera general cómo viven en Girona, su relación con la población local y los nexos transnacionales con Honduras.

Como conclusión, el contenido de los nueve textos tiene como hilo conductor lo que Immanuel Wallerstein planteó como la Teoría del Sistema-Mundo, ${ }^{1}$ donde el sistema capitalista global se basa en grandes capitales transnacionales, la aplicación de políticas de ajuste neoliberal que produce asimetrías entre centro y periferia y una economía basada en la exportación de fuerza de trabajo, en la cual prevalece la dualidad entre el rechazo a la migración y la sostenibilidad de los sistemas de seguridad social y pensiones. En este escenario, tal como lo indican varios autores a lo largo del libro, las migraciones en Centroamérica están entretejidas dentro de un sistema neoliberal que se beneficia de los desplazamientos a través de las remesas económicas y sociales, pero también de la disponibilidad de una fuerza laboral flexible y precaria puesta (como mercancía) al servicio de la economía capitalista desde la periferia.

\section{Nota}

1 Martínez Martín, A. Reflexiones en torno al Sistema Mundo de Immanuel Wallerstein. Revista Historia y Memoria, 2(2011): 211-220. Recuperado de https://www.redalyc.org/ pdf/3251/325127478010.pdf 
Aracely J. Martínez Rodas. Antropóloga guatemalteca de la Universidad del Valle de Guatemala, cuenta con un Máster en Cooperación al Desarrollo por la Universidad Pontificia de Comillas, Madrid, en donde obtuvo el Doctorado de Migraciones Contemporáneas con la tesis Las organizaciones de migrantes guatemaltecos como actores transnacionales: las experiencias de Los Ángeles, California y Omaha, Nebraska (2016). Ha trabajado como consultora independiente para diversas ONG y organismos internacionales. Es miembro individual del Grupo Articulador de la Sociedad Civil en Materia Migratoria, y de la Plataforma Migración y Desarrollo, docente e investigadora de la Facultad de Ciencias Sociales de la Universidad del Valle de Guatemala y Directora del Departamento de Maestría en Desarrollo de dicha casa de estudios.

Contacto: ajmartinez@uvg.edu.gt

ORCID: 0000-0001-8985-9628 